\title{
湖南东部植被恢复对土壤有机碳矿化的影响
}

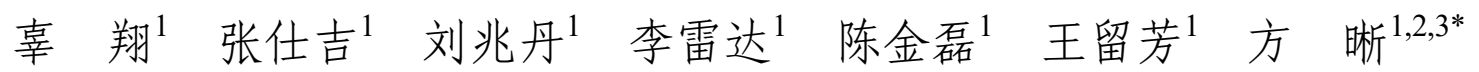

${ }^{1}$ 中南林业科技大学生命科学与技术学院, 长沙 $410004 ;{ }^{2}$ 南方林业生态应用技术国家工程实验室, 长沙 410004 ; ${ }^{3}$ 湖南会同杉木林生态系统国家野外 科学观测研究站, 湖南会同 438107

摘 要 为阐明中亚热带植被恢复对土壤有机碳(SOC)稳定性的影响机制, 采用空间代替时间方法, 在湘东丘陵区选取聯木 (Loropetalum chinense)-南烛(Vaccinium bracteatum)-杜鹃 (Rhododendron simsii)灌草丛(LVR)、皪木-杉木(Cunninghamia lanceolata)-白栋(Quercus fabri)灌木林(LCQ)、马尾松(Pinus massoniana)-柯(Lithocarpus glaber)-聯木针阔混交林(PLL)、柯-红 淡比(Cleyera japonica)-青冈(Cyclobalanopsis glauca)常绿阔叶林(LAG)作为一个恢复系列, 采用室内恒温培养(碱液吸收法)测 定 $\mathrm{SOC}$ 矿化速率及其累积矿化量 $\left(C_{\mathrm{m}}\right)$, 结合主成分和逐步回归方法分析 $C_{\mathrm{m}} 、 \mathrm{SOC}$ 矿化率与植被因子和土壤因子的关系。结果 表明: (1)不同植被恢复阶段SOC矿化速率随着培养时间呈现基本一致的变化趋势, 培养初期矿化速率较高, 且快速下降，培 养中后期缓慢下降并趋于平稳, 倒数方程能很好地拟合不同植被恢复阶段SOC矿化速率与培养时间的关系。(2)植被恢复显著 提高各土层SOC矿化速率和 $C_{\mathrm{m}}, \mathrm{LAG}$ 显著高于其他 3 个植被恢复阶段, LAG 0-40 $\mathrm{cm}$ 土层 $C_{\mathrm{m}}$ 比LVR、LCQ、PLL分别高出 $359.06 \%-716.31 \% 、 112.38 \%-232.61 \% 、 94.40 \%-105.74 \%$ 。(3) 4种植被恢复阶段0-10、10-20、20-30、30-40 cm土层SOC矿 化率分别为 $2.13 \%-4.99 \% 、 3.42 \%-4.18 \% 、 4.05 \%-4.64 \% 、 4.02 \%-5.64 \%$, 但不同植被恢复阶段之间差异不显著。(4)植被恢复 过程中, $C_{\mathrm{m}}$ 的变化主要受土壤全氮 $(\mathrm{TN})$ 含量、根系生物量的驱动, 土壤 $\mathrm{TN}$ 含量、根系生物量可分别解释 $C_{\mathrm{m}}$ 变异的 $96.9 \%$ 、 $0.9 \%$ 。而土壤 C:N是SOC矿化率的主要调控因子, 可单独解释SOC矿化率变异的 $49.4 \%$ 。表明植被恢复促进了 SOC矿化, 降低 了 $\mathrm{SOC}$ 中矿化 $\mathrm{C}$ 的比例, 有利于提高土壤固 $\mathrm{C}$ 能力; 随着植被恢复, 土壤 $\mathrm{TN}$ 含量和根系生物量增加是影响 $C_{\mathrm{m}}$ 的主要因子, 而 土壤SOC的质量差异是影响SOC矿化率的主要因子。

关键词 中亚热带地区; 植被恢复; 有机碳矿化; 植被因子; 土壤因子

辜翔, 张仕吉, 刘兆丹, 李雷达, 陈金磊, 王留芳, 方晰 (2018). 湖南东部植被恢复对土壤有机碳矿化的影响. 植物生态学报, 42, 1211-1224. DOI: 10.17521/cjpe.2018.0202

\section{Effects of vegetation restoration on soil organic carbon mineralization in the east of Hunan, China}

GU Xiang ${ }^{1}$, ZHANG Shi-Ji ${ }^{1}$, LIU Zhao-Dan ${ }^{1}$, LI Lei-Da ${ }^{1}$, CHEN Jin-Lei ${ }^{1}$, WANG Liu-Fang ${ }^{1}$, and FANG Xi ${ }^{1,2,3^{*}}$

${ }^{1}$ School of Life Science and Technology, Central South University of Forestry and Technology, Changsha 410004, China; ${ }^{2}$ National Engineering Laboratory of South China Forestry Ecology Applicable Technologies, Changsha 410004, China; and ${ }^{3}$ Huitong National Field Station for Scientific Observation and Research of Chinese Fir Plantation Ecosystem in Hunan Province, Huitong, Hunan 438107, China

\begin{abstract}
Aims Soil organic carbon (SOC) mineralization and its controlling factors are critical for understanding the mechanisms that regulate $\mathrm{C}$ storage and loss processes. Our objectives were to accurately assess the impacts of vegetation restoration on SOC mineralization and to illustrate the underlying mechanism of changes in SOC stability with vegetation restoration in the mid-subtropical region of China.

Methods Four types of vegetation communities (Loropetalum chinense-Vaccinium bracteatum-Rhododendron mariesii scrub-grass-land (LVR), Loropetalum chinense-Cunninghamia lanceolata-Quercus fabri shrubbery (LCQ), Pinus massoniana-Lithocarpus glaber-Loropetalum chinense coniferous-broad leaved mixed forest (PLL) and Lithocarpus glaber-Cleyera japonica-Cyclobalanopsis glauca evergreen broad-leaved forest (LAG) ) were selected for a successional sequence of the secondary forest in a hilly region of eastern Hunan Province, China. Soil samples $(0-40 \mathrm{~cm})$ were collected from four depths $(0-10,10-20,20-30$ and 30-40 cm). SOC mineralization was determined by the laboratory incubation method (alkali absorption method). Principal component analysis and stepwise regression were applied to analyze the relationships between SOC cumulative mineralization $\left(C_{\mathrm{m}}\right)$,

收稿日期Received: 2018-08-16 接受日期Accepted: 2018-11-01

基金项目：国家林业公益性行业科研专项(201504411)和国家自然科学基金项目(30771720和31170426)。 Supported by the National Forestry Public Welfare Industry Research Project (201504411), and the National Natural Science Foundation of China (30771720 and 31170426 ).

* 通信作者Corresponding author (fangxizhang@sina.com)
\end{abstract}


the percentage of $C_{\mathrm{m}}$ to $\mathrm{SOC}$ content and vegetation factors and soil factors.

Important findings 1) SOC mineralization rate displayed similar trends during the four restoration stages: during the early incubation period, SOC mineralization was high and decreased fast, and then the rate decreased slowly and tend to stabilize during the middle and late periods. The pattern was well fitted with the reciprocal equation. 2) SOC mineralization rate and $C_{\mathrm{m}}$ increased significantly with the vegetation restoration stage with the LAG having both the highest SOC mineralization rate and the highest $C_{\mathrm{m}}$. In $0-40 \mathrm{~cm}$ soil layer, $C_{\mathrm{m}}$ in LAG soil was $359.06 \%-716.31 \%, 112.38 \%-232.61 \%, 94.40 \%-105.74 \%$ higher than that in LVR, LCQ, PLL soils, respectively. 3) The percentage of $C_{\mathrm{m}}$ to SOC content were $2.13 \%-4.99 \%, 3.42 \%-4.18 \%, 4.05 \%-4.64 \%$, and $4.02 \%-$ $5.64 \%$ in $0-10,10-20,20-30,30-40 \mathrm{~cm}$ soil layers, respectively. However, there was no significant difference in the percentage of $C_{\mathrm{m}}$ to SOC content among the different restoration stages. 4) Among different vegetation restoration stages, total nitrogen (TN) content and root biomass (RB) were the key factors affecting $C_{\mathrm{m}}$. TN content and $\mathrm{RB}$ together explained $97.8 \%$ variations in $C_{\mathrm{m}}$, of which $\mathrm{TN}$ content explained $96.9 \%$. However, $\mathrm{C}: \mathrm{N}$ was the dominant factor affecting the percentage of $C_{\mathrm{m}}$ to SOC content and it alone explained $49.4 \%$ variation. Vegetation restoration promoted SOC mineralization rate and reduced the percentage of $C_{\mathrm{m}}$ to SOC content in our study, which might be related to the changes in RB and soil nutrient during vegetation restoration.

Key words mid-subtropical region of China; vegetation restoration; soil organic carbon mineralization; vegetation factor; soil factor

Gu X, Zhang SJ, Liu ZD, Li LD, Chen JL, Wang LF, Fang X (2018). Effects of vegetation restoration on soil organic carbon mineralization in the east of Hunan, China. Chinese Journal of Plant Ecology, 42, 1211-1224. DOI: 10.17521/cjpe.2018.0202

\section{土壤有机碳(SOC)矿化是土壤碳(C)输出的主要} 途径, 是大气中 $\mathrm{CO}_{2}$ 的重要来源, 在维持全球 $\mathrm{C}$ 平衡 中具有极其重要的作用(Saggar et al., 2001; Craine et al., 2010)。SOC矿化不仅反映SOC的稳定性和周 转(周玉燕等, 2011; 黄宗胜等, 2012), 而且关系到 土壤养分元素的释放与供应。因此, 研究SOC矿化 特征及其影响因素是陆地生态系统 $\mathrm{C}$ 循环的研究热 点, 有助于揭示 $\mathrm{SOC}$ 释放的驱动机制及其稳定性, 为深入研究土壤固 $\mathrm{C}$ 能力的影响机制和估算土壤 $\mathrm{C}$ 平衡提供基础数据, 而且对科学管理土壤养分, 有 效缓解全球气候变暖具有重要意义(Zhu et al., 2017)。

植被恢复是影响陆地生态系统 $\mathrm{C}$ 循环的重要因 素, 不仅显著地影响森林与大气之间 $\mathrm{C}$ 交换过程(范 跃新等, 2014), 而且还会影响土壤在全球 $\mathrm{C}$ 收支平 衡中是“源”还是“汇”的功能(邬建红等, 2015)。随着 植被恢复, 地上植被类型、植物群落组成和结构不 断变化, 调落物、根系的数量和质量随之改变, 必然 会影响土壤物理、化学和生物学性质, 进而影响 SOC矿化过程(Li et al., 2004; 李杨梅等, 2017)。近 年来, 国内外学者陆续开展了植被恢复对 SOC矿化 影响的研究, 但不同的研究所取得的结果不尽相 同。研究表明, 由于生态系统净初级生产力和生物 量在植被恢复初期显著增加, 之后逐渐降低, 因而 SOC矿化速率也随着植被恢复呈先逐渐增加, 后保
持稳定或略有下降的趋势(范跃新等, 2014)。Zhu等 (2017)也证实, SOC累积矿化量随茶树人工林恢复 先增加后略微减少。但也有研究发现, SOC矿化速率 随着植被恢复逐渐增大(邵月红等, 2005), 增加了 $29 \%$ (吴建国等, 2004)。此外, 还有研究发现, 退耕 还林(水稻(Oryza sativa)田恢复为落叶阔叶林)后土 壤 $\mathrm{CO}_{2}$ 平均释放量下降 $53.4 \%$, 可能是由于测定时 水稻田处于旱作期, 微生物活性不受水分限制, 翻 耕等人为活动将深土层土壤暴露于空气中, 显著促 进了水稻田 $\mathrm{SOC}$ 矿化, 导致水稻田土壤 $\mathrm{CO}_{2}$ 平均释 放量高于落叶阔叶林(Cui et al., 2013)。杨树(Populus spp.)林恢复过程中, 土壤 $\mathrm{CO}_{2}$ 释放量呈先降低后升 高的趋势(Sun et al., 2015)。由于SOC矿化是一个复 杂的生态学过程, 研究结果的不一致性不是某一个 因子造成的。综观现有植被恢复对SOC矿化影响的 研究, 主要集中在人工恢复植被方式如退耕还林 (Zhao et al., 2008; 刘苑秋等, 2011)、草地造林(Ross et al., 2002; 胡亚林等, 2007)、不同年龄人工林植被 (Sun et al., 2015; 张浩等, 2016)或不同森林类型(杨 开军等, 2017)对SOC矿化的影响, 有关退化植被自 然恢复对 SOC矿化影响的研究仍鲜有报道。此外, 现有的研究大多仅考虑某单一影响因子(如温度、水 分、土壤理化性质)对SOC矿化的影响, 较少考虑植被 因子、土壤因子对SOC矿化的综合影响, 因此, 对植 被恢复过程中SOC矿化特征及其驱动力的规律性认 
识仍非常有限，限制了人们对全球气候变化下未来 中亚热带森林生态系统变化趋势的准确估测(ScottDenton et al., 2003; 张玲等, 2017), 因此系统研究 植被恢复过程中SOC矿化特征及其驱动机制将有助 于准确估测森林生态系统 $\mathrm{C}$ 收支能力及其未来动态。

常绿阔叶林是中国亚热带地区植被进展演替的 顶极植被类型, 也是当前国际生态学研究的热点之 一(宋新章等, 2009)。为保护生物多样性和提升森林 生态系统生态功能, 20 世纪 90 年代以来, 中国政府 实施了天然林保护等一系列林业生态工程, 中亚热 带地区森林植被恢复迅速。但由于受到不同程度的 人为干扰，植被恢复程度及物种组成不同，形成了 多种处于不同恢复阶段的植物群落。随着植被恢复, 群落组成、结构趋于复杂, 生物量提高, 调落物、根 系的数量和质量逐渐变化, 土壤理化性质也随之发 生改变(项文化和方晰, 2018)。然而, 随着植被恢复, SOC矿化特征呈现怎样的变化规律, 植被恢复导致 土壤理化性质的改变对土壤 $\mathrm{C}$ 的稳定性产生怎样的 影响, SOC矿化的驱动机制是什么, 这些问题迄今 仍缺乏系统研究。因此, 人们对森林植被恢复过程 中, 土壤活性 $\mathrm{C}$ 库动态与生态系统过程的联系还知 之甚少, 对影响土壤 $\mathrm{C}$ 动态因素的理解仍然显得比 较零碎(Milcu et al., 2011)。为此, 本研究采用空间 代替时间的方法, 在湘东丘陵区选取处于不同植被 恢复阶段的4种林地: 聯木(Loropetalum chinensis)南烛 (Vaccinium bracteatum)- 杜鹃 (Rhododendron mariesii)灌草丛、聯木-杉木(Cunninghamia lanceolata)-白柇(Quercus fabri) 灌木林、马尾松 (Pinus massoniana)-柯(又名石柇)(Lithocarpus glaber)-聯木 针阔混交林、柯-红淡比(Adinandra millettii)-青冈 (Cyclobalanopsis glauca) 常绿阔叶林为研究对象, 基于 94 天室内恒温培养的SOC矿化数据, 探讨植被 恢复过程中, SOC矿化速率、累积矿化量 $\left(C_{\mathrm{m}}\right)$ 以及矿 化率的变化规律, 分析植被因子、土壤因子对 $\mathrm{SOC}$ 矿化过程的影响, 旨在揭示中亚热带植被恢复过程 中 SOC矿化特征及其与群落植被一土壤基质协同变 化规律与驱动机制, 为提高森林土壤固 $C$ 潜力和科 学管理土壤C库提供科学依据。

\section{1 材料和方法}

\section{1 研究地概况}

研究地设置在湖南省东部偏北的长沙县(113.28- $113.45^{\circ} \mathrm{E}, 28.38-28.40^{\circ} \mathrm{N}$; 图1), 地处湘江下游，长 衡丘陵盆地的北部, 幕阜山与大龙山余脉的南端, 属于典型低山丘陵区, 地形起伏较大, 海拔 55-550 $\mathrm{m}$, 坡度多在 $20^{\circ}-30^{\circ}$ 。为中亚热带东南季风湿润气 候, 由于地处东亚季风环流区, 受东夏季风转换、复 杂地形等因素的影响, 该地区气候具有春季温度变 化大、夏初雨水多、秋季高温干燥时间长、冬季严 寒期短的特点。年平均气温 $17.0{ }^{\circ} \mathrm{C}$, 极端高温为 $39.8{ }^{\circ} \mathrm{C}$ (7-8月份), 极端低温 $-10.3{ }^{\circ} \mathrm{C}$ (1月份), 无 霜期269-300天, 雨量充沛, 相对湿度较大, 年降水 量1 412-1 $559 \mathrm{~mm}$, 主要集中于4-7月份, 平均年日 照时间 $1440 \mathrm{~h}$ 。土壤以板岩和页岩发育而成的酸性 红壤为主, 土质黏重, 富含铁、铝氧化物, 养分含量 低, 保肥性能较差。原生地带性植被为亚热带常绿 阔叶林, 主要有柯、青冈、樟(Cinnamomum camphora)、椤木石楠(Photinia davidsoniae)、朝鲜木姜 子(Litsea coreana)、南酸畨(Choerospondias axillaris)、雉栗(Castanea henryi)、枫香(Liquidambar formosana) 等树种。由于长期的人为活动干扰(采伐、 火烧、放牧)和集约的土地利用，原生地带性森林植 被常绿阔叶林已遭到严重的破坏。20世纪90年代初, 中国政府实施了天然林保护等一系列林业生态工程, 形成了多种处于不同恢复演替阶段的次生植物群落 (灌草丛、灌木林、针阔混交林、常绿阔叶林), 为 开展中亚热带森林植被恢复演替研究提供了良好的 场所。

\section{2 样地设置和群落调查}

2015年10月，采用空间差异代替时间序列的方 法, 按照中亚热带森林群落自然演替进程, 根据人 为干扰程度、植被恢复程度及其群落树种组成, 选 取地域相邻、坡度、海拔、土壤和气候等立地条件 基本一致，处于不同恢复阶段的4种植物群落: (1)恢 复早期介段: 1965年天然常绿阔叶林采伐后, 炼山、 人工整地，1966年营造马尾松人工林, 无施肥历史, 1990年马尾松人工林皆伐。1991年以来, 不断受到 砍伐、火烧、放牧等人为干扰, 2012 年停止人为干扰。 当前自然恢复为聯木-南烛-杜鹃灌草丛群落(LVR)。 (2)恢复中期I阶段: 1965年天然常绿榈叶林采伐后, 炼山、人工整地, 1966年营造杉木人工林, 无施肥历 史, 1989-1990年皆伐杉木人工林。之后每隔3-5年对 群落中的灌木、杉木萌芽条择伐一次, 直到2004年 停止择伐。当前自然恢复为聯木-杉木-白栋灌木林 
群落(LCQ)。(3)恢复中期II阶段：20世纪60年代末, 天然常绿阔叶林采伐后自然恢复为马尾松-柯-㶌木 针阔混交林群落(PLL)。(4)恢复后期(亚顶极)阶段: 长期以来无明显人为干扰, 保存比较完好的柯-红 淡比-青冈常绿阔叶林群落(LAG), 群落结构相对稳 定，林龄80-90年。在LVR群落设置4块 $20 \mathrm{~m} \times 20 \mathrm{~m}$ 的长期定位观测样地, 在 $\mathrm{LCQ}$ 群落设置 3 块 $20 \mathrm{~m} \times$ $20 \mathrm{~m}$ 的长期定位观测样地, 在PLL、LAG群落分别设 置3块 $30 \mathrm{~m} \times 30 \mathrm{~m}$ 的长期定位观测样地, 如图1所示。

采用样方调查法, 2016年10-11月落叶树种落叶 前完成群落调查, 所有植物均鉴定到种(辜翔等, 2018)。(1)在LVR样地, 沿对角线均匀设置 4 个 $2 \mathrm{~m} \times$ $2 \mathrm{~m}$ 样方, 记录灌木层、草本层植物种类、株数、平 均高度等。(2)在LCQ样地, 沿对角线均匀设置 4 个 $5 \mathrm{~m} \times 5 \mathrm{~m}$ 样方, 记录灌木层植物种类、株数、平均 高度等, 对树高 $>1.5 \mathrm{~m}$ 的灌木进行挂牌编号, 测定 胸径 $(D B H)$ 、树高、冠幅、枝下高等; 对树高 $<1.5 \mathrm{~m}$ 的灌木, 测定地径和树高; 草本层植物调查方法与 LVR样地草本层植物调查方法相同。(3)在PLL、LAG 样地, 对树高 $>1.5 \mathrm{~m}$ 的木本植物进行挂牌编号, 记 录植物种类, 测定胸径、树高、冠幅、枝下高等; 灌 木层、草本层植物调查方法与LCQ样地灌木层、草 本层植物的调查方法相同。计算4种植物群落木本植

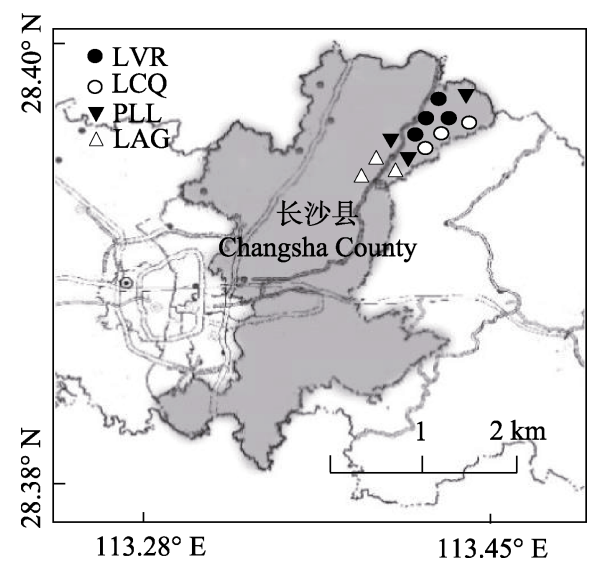

图1 湖南东部不同恢复阶段植物群落样地的地理位置和分

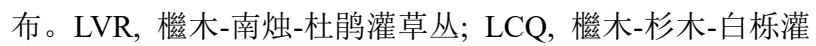
木林; PLL, 马尾松-柯-皪木针阔混交林; LAG, 柯-红淡比-青 冈常绿阔叶林。

Fig. 1 The location and distribution of the different vegetation communities in the east of Hunan Province. LVR, Loropetalum chinense-Vaccinium bracteatum-Rhododendron mariesii scrubgrass-land; LCQ, Loropetalum chinense-Cunninghamia lanceolataQuercus fabri shrubbery; PLL, Pinus massoniana-Lithocarpus glaber-Loropetalum chinense coniferous-broad leaved mixed forest; LAG, Lithocarpus glaber-Cleyera japonica-Cyclobalanopsis glauca evergreen broad-leaved forest.
物的密度、平均胸径、平均树高, Shannon-Wiener 多样性指数等。4种群落的基本特征及其主要树种组 成详见幸翔等(2018)的文献。

\section{3 群落生物量的测定}

2016年10月, 在样地群落调查基础上, 采用收 获法和建立主要树种各器官生物量相对生长方程, 测定群落生物量(辜翔等, 2018)。4种植被恢复阶段 群落生物量特征如表1所示。

\section{4 凋落物层现存量的测定及其分析样品的采集、 处理和分析方法}

2016年10月，在每个样地的对角线均匀布置 3 个 $1 \mathrm{~m} \times 1 \mathrm{~m}$ 样方, 采集样方内的全部调落物, 称湿 质量后采集分析样品约 $1.0 \mathrm{~kg}$ (㙜翔等, 2018)。在室 内 $80{ }^{\circ} \mathrm{C}$ 烘干称干质量后, 经植物粉碎机磨碎, 过 60 目篮孔保存于样品瓶中, 用于测定有机碳(LC)、全 氮(LN)、全磷(LP)、木质素(LL)含量; 根据分析样品 湿质量与烘干质量的比例估算各样地凋落物层现存 量。

LC、LN、LP含量的测定详见辜翔等(2018)的文 献, LL含量测定采用Van-Soest法(Reza et al., 2014) 测定。每个分析样品平行测定 2 次, 取平均值作为该 样品的最终测定结果。4种植被恢复阶段调落物层养 分特征如表1所示。

\section{5 土壤分析样品采集、处理和分析方法}

2016年10月, 完成调落物层分析样品采集后, 在 $1 \mathrm{~m} \times 1 \mathrm{~m}$ 样方内挖掘土壤剖面, 分层 $(0-10$ 、 10-20、20-30、30-40 cm) 采集土壤样品, 装入无菌 塑料袋密封, 放入便携式冷藏箱, 带回实验室。在室 内, 将同一样地 3 个样方相同土层的土壤样品等量 混合为 1 个样品, 去除植物调落物、根系和石块, 过 2 $\mathrm{mm}$ 土壤篮后, 每 1 个鲜土样品分成 2 份。其中 1 份放 入冰箱 $0-4{ }^{\circ} \mathrm{C}$ 低温保存, 用于测定 SOC矿化量。另 1 份自然风干，再分成3等份： 1 份过 $2 \mathrm{~mm}$ 土壤篮，用 于测定土壤颗粒组成; 1 份过 $1 \mathrm{~mm}$ 土壤篮, 用于测 定 $\mathrm{pH}$ 值; 另一份过 $0.25 \mathrm{~mm}$ 土壤篎, 用于测定 $\mathrm{SOC} 、$ 全氮(TN)、全磷 $(\mathrm{TP})$ 含量。

土壤容重、土壤颗粒分级、土壤 $\mathrm{pH} 、 \mathrm{SOC} 、 \mathrm{TN}$ 、 TP含量的测定详见啈翔等(2018)的文献。每个分析 样品平行测定 2 次, 取平均值作为该样品的最终测 定结果。 4 个植物群落土壤理化性质如表 2 所示。

SOC矿化用室内恒温培养、碱液吸收酸滴定法 (文启孝, 1984; Qian et al., 2013), 具体步骤: 称取过 

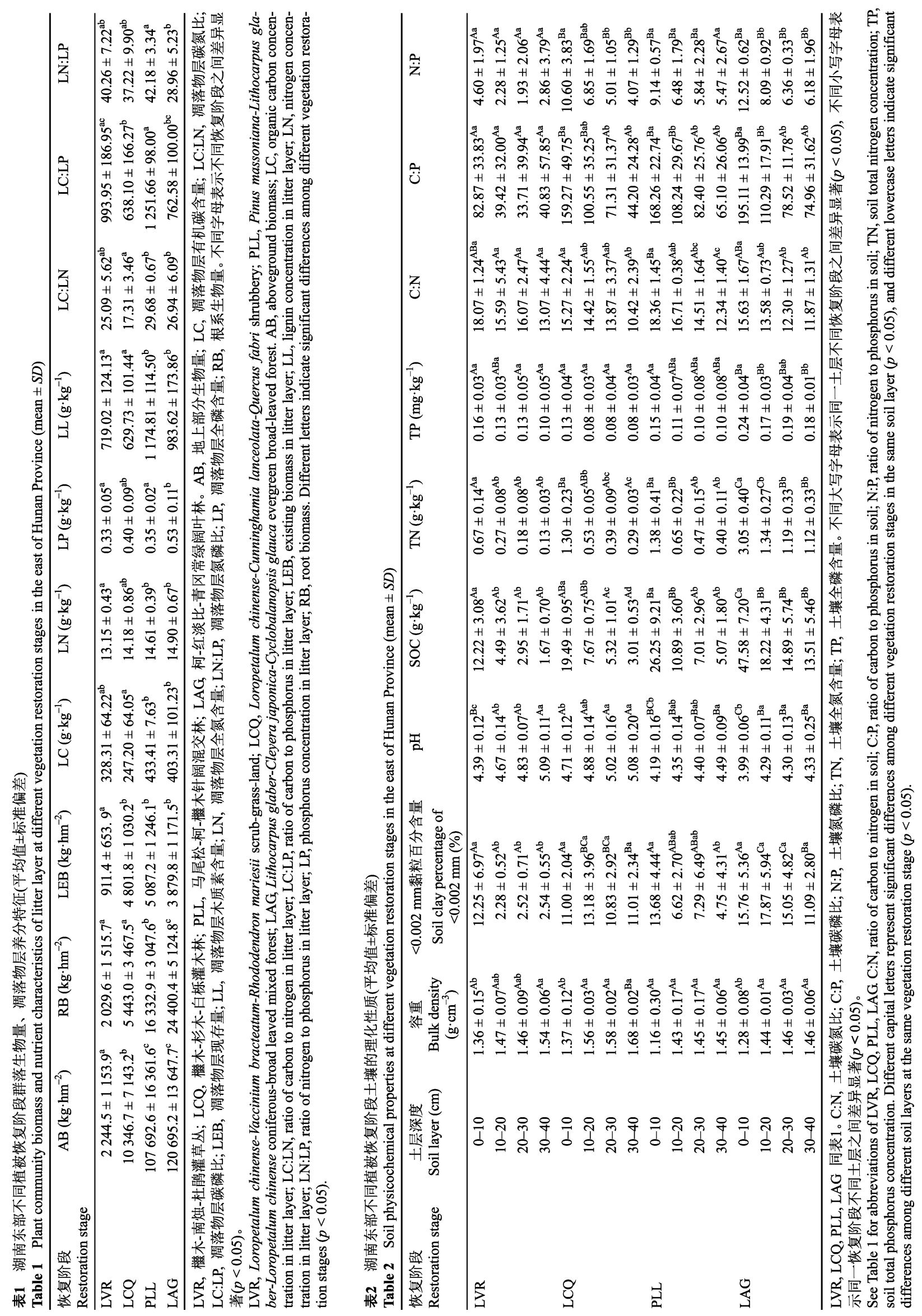
$2 \mathrm{~mm}$ 土壤筛的新鲜土壤样品 $50.00 \mathrm{~g}$ 置于 $500 \mathrm{~mL}$ 带 有橡皮塞的广口瓶中, 内置装有 $10 \mathrm{~mL} 0.2 \mathrm{~mol} \cdot \mathrm{L}^{-1}$ $\mathrm{NaOH}$ 溶液的 $50 \mathrm{~mL}$ 塑料吸收瓶, 用以吸收 $\mathrm{SOC}$ 矿化 释放的 $\mathrm{CO}_{2}$, 密封广口瓶后, 分批次置于 $35{ }^{\circ} \mathrm{C}$ 恒温 培养箱培养94天, 用蒸馏水调节土壤含水量至土壤 最大持水量的 $60 \%$ 。在培养的第 $3 、 6 、 9 、 13 、 17$ 、 $21 、 28 、 35 、 42 、 49 、 64 、 79 、 94$ 天将吸收液取出 并换上新的吸收瓶，再按上述方法继续培养，同时 进行空白试验; 取出的 $\mathrm{NaOH}$ 吸收液, 加入 $3 \mathrm{~mL} 1.5$ $\mathrm{mol} \cdot \mathrm{L}^{-1} \mathrm{BaCl}_{2}$ 溶液, 以酚酞为指示剂(溶液显红色), 用 $0.1 \mathrm{~mol} \cdot \mathrm{L}^{-1}$ 的 $\mathrm{C}_{6} \mathrm{H}_{4} \mathrm{COOHCOOK}$ (苯二甲酸氢钾) 滴定中和剩余的 $\mathrm{NaOH}$ 溶液 (溶液呈无色为终点)。根 据 $\mathrm{C}_{6} \mathrm{H}_{4} \mathrm{COOHCOOK}$ 的消耗量计算出 $\mathrm{SOC}$ 矿化量 (即 $\mathrm{CO}_{2}-\mathrm{C}$ 的释放量, $\mathrm{g} \cdot \mathrm{kg}^{-1}$ )。每个土壤样品平行测定 2次, 取平均值作为该土壤样品的最终测定值。

\section{6 数据统计处理}

Shannon-Wiener多样性指数用如下公式计算:

$$
S I=-\sum_{i=1}^{S} P_{i} \ln P_{i}
$$

式(1)中, $S$ 为群落中物种总数; $P_{i}$ 为群落中物种 $i$ 的相 对频度。

各土层 $\mathrm{SOC}$ 矿化释放的 $\mathrm{CO}_{2}-\mathrm{C}$ 量 $\left(\mathrm{g} \cdot \mathrm{kg}^{-1}\right)$ 用如下 公式计算:

$$
\mathrm{CO}_{2}-\mathrm{C}=\frac{6 \times C H\left(V_{0}-V\right)}{W \times k}
$$

式(2)中, 6 为 $\mathrm{CO}_{2}$ 的摩尔质量换算为 $\mathrm{C}$ 的摩尔质量的 转换系数; $\mathrm{CH}$ 为 $\mathrm{C}_{6} \mathrm{H}_{4} \mathrm{COOHCOOK}$ 标准溶液浓度 $\left(\mathrm{mol} \cdot \mathrm{L}^{-1}\right) ; V_{0}$ 为空白 $\mathrm{NaOH}$ 溶液所消耗的 $\mathrm{C}_{6} \mathrm{H}_{4} \mathrm{COOHCOOK}$ 溶液体积数 $(\mathrm{mL}) ; \mathrm{V}$ 为土壤样品残 留的 $\mathrm{NaOH}$ 溶液所消耗的 $\mathrm{C}_{6} \mathrm{H}_{4} \mathrm{COOHCOOK}$ 溶液体 积数 $(\mathrm{mL}) ; W$ 为新鲜土壤样品质量 $(\mathrm{g}) ; k$ 为新鲜土壤 质量换算为烘干土壤质量的转换系数。

SOC矿化速率(即日均矿化量)是单位干土每天 矿化释放的 $\mathrm{C}$ 数量 $\left(\mathrm{g} \cdot \mathrm{kg}^{-1} \cdot \mathrm{d}^{-1}\right)$; SOC 累积矿化量 $\left(C_{\mathrm{m}}\right)$ 是培养94天内, 单位干土 $S O C$ 矿化释放的 $C$ 的总量 $\left(\mathrm{g} \cdot \mathrm{kg}^{-1}\right)$; SOC矿化率 $\left(C_{\mathrm{m}} / \mathrm{SOC}\right)$, 是一定培养时间内, $\mathrm{SOC}$ 矿化释放的C量占 $\mathrm{SOC}$ 含量的百分比 $(\%)$ 。

运用Excel 2010和SPSS 22.0统计软件进行数据 统计分析, 运用Sigmaplot 12.5软件制图。用Excel 2010 统计各项指标平均值和标准偏差。由于SOC矿 化释放的 $\mathrm{C}$ 量随着培养时间的增加而衰减, 但不是 直线下降, 因此用SPSS 22.0 统计软件中的倒数方程
和指数方程对SOC矿化速率与培养时间的关系进行 拟合, 与指数方程相比, 倒数方程的相关系数更大, 更能准确地反映出SOC矿化速率与培养时间的关系; 用单因素方差分析的最小显著差数法 $(L S D, p<0.05)$ 检验不同恢复阶段群落生物量(地上部分生物量、根 系生物量、调落物层现存量)、调落物层养分特征 $(\mathrm{C}$ 、 $\mathrm{N} 、 \mathrm{P}$ 含量及 $\mathrm{C}: \mathrm{N} 、 \mathrm{~N}: \mathrm{P} 、 \mathrm{C}: \mathrm{P})$ 和SOC矿化速率的差异 显著性，检验不同恢复阶段、不同土层土壤理化性 质(容重、颗粒组成、 $\mathrm{pH}$ 值、SOC、TN、TP含量和 $\mathrm{C}: \mathrm{N} 、 \mathrm{~N}: \mathrm{P} 、 \mathrm{C}: \mathrm{P})$ 和 $C_{\mathrm{m}}$ 的差异显著性; 用Pearson相关 系数分析 $\mathrm{SOC}$ 矿化速率和 $C_{\mathrm{m}}$ 与植被因子和土壤因 子的相关性; 用主成分分析方法分析影响研究地 $\mathrm{SOC}$ 矿化速率变化的主要影响因子; 为定量分析各 因子对 $C_{\mathrm{m}}$ 和 $C_{\mathrm{m}} / \mathrm{SOC}$ 的影响程度, 用逐步回归分析 主成分分析得到的指标, 笁选出对 $C_{\mathrm{m}}$ 和 $C_{\mathrm{m}} / \mathrm{SOC}$ 矿 化影响较大的因素, 方程引入变量的标准为变量 $F$ 值的 $p \leqslant 0.05$, 剔除变量的标准为 $p>0.1$, 并采用 统计量 $t$ 对回归方程进行检验, 通过回归方程的调 整判定系数, 量化各因子对 $C_{\mathrm{m}}$ 和 $C_{\mathrm{m}} / \mathrm{SOC}$ 变异的相 对重要性和综合解释能力, 确定影响 $C_{\mathrm{m}}$ 和 $C_{\mathrm{m}} / \mathrm{SOC}$ 的主要因子。

\section{2 结果和分析}

\subsection{SOC的矿化速率}

由图2可知, 不同植被恢复阶段 $\mathrm{SOC}$ 矿化速率 随培养时间的变化基本一致, 即 $\mathrm{SOC}$ 平均矿化速率 在培养初期(第3-17天)较高且快速下降, 随后缓慢 下降并逐渐趋于平稳。回归分析结果(表3)表明, 培 养期间不同植被恢复阶段SOC矿化速率随培养时间 的变化符合倒数方程, 拟合效果均达到极显著水平 $(p<0.01)$ 。表明SOC矿化速率具有培养初期较高、 培养中后期降低并趋于平稳的阶段性特征, 且不随 着植被恢复而有明显的改变。

同一土层同一培养时间, SOC矿化速率随着植 被恢复呈增大趋势, 且不同植被恢复阶段差异显著 $(p<0.05) ; 0-10 \mathrm{~cm}$ 土层, LAG与LVR、LCQ、PLL之 间，LCQ、PLL与LVR之间差异显著 $(p<0.05)$, 而 LCQ与PLL差异不显著 $(p>0.05) ; 10-20 、 20-30$ 、 30-40 cm土层, LAG与LVR、LCQ、PLL差异显著 $(p<$ $0.05)$, 但LVR、LCQ、PLL两两之间差异不显著 $(p>$ $0.05)$ 。表明植被恢复显著影响SOC矿化速率, 但影 响程度随土层深度增加而减弱(图2)。 

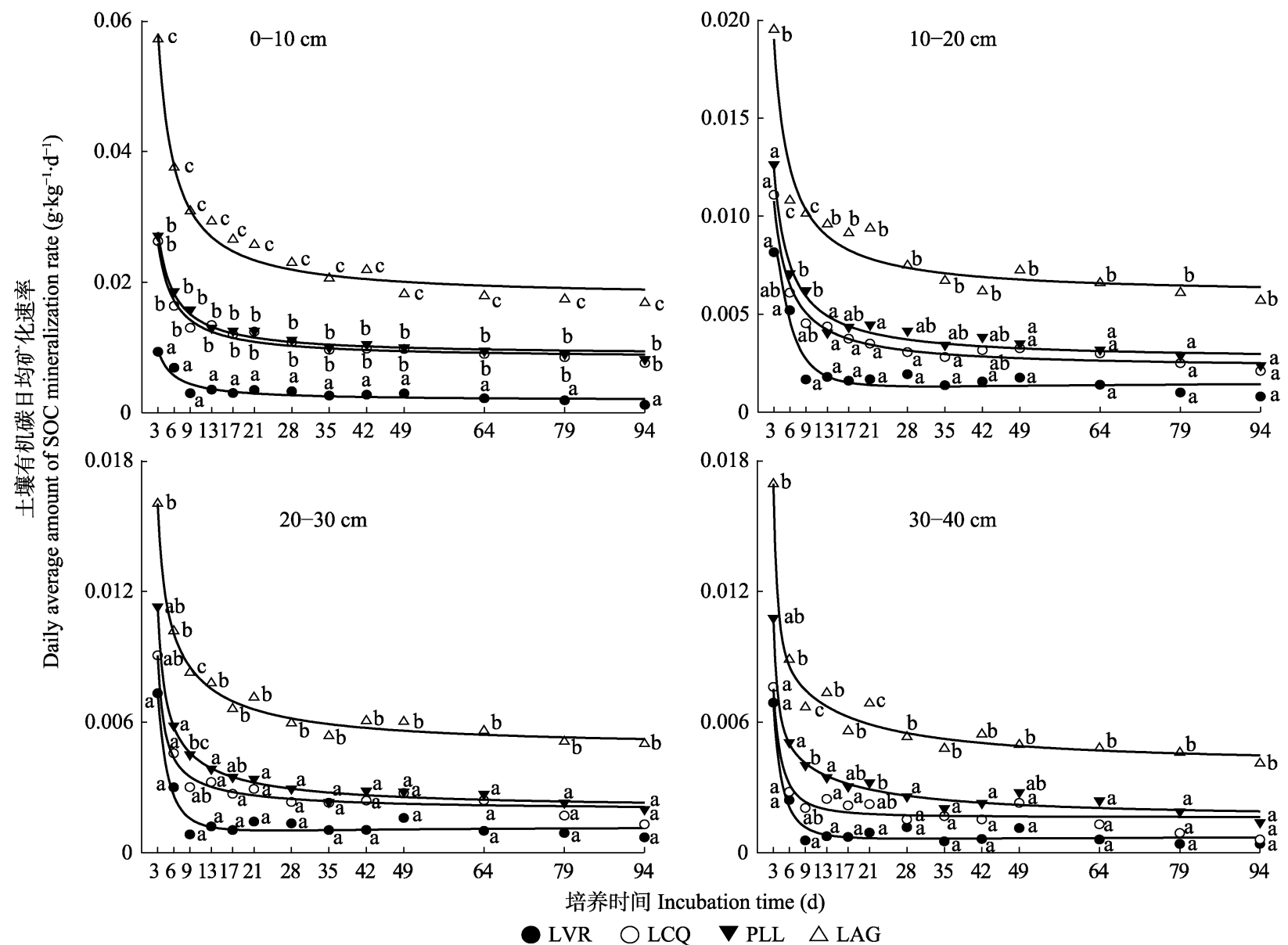

图 2 湖南东部不同植被恢复阶段土壤有机碳矿化速率。LVR，聯木-南烛-杜鹃灌草丛; LCQ, 檵木-杉木-白栎灌木林; PLL，马 尾松-柯-聯木针阔混交林; LAG，柯-红淡比-青冈常绿阔叶林。不同字母表示同一培养时间同一土层不同植被恢复阶段之间差 异显著 $(p<0.05)$ 。

Fig. 2 Soil organic carbon (SOC) mineralization rate at different vegetation restoration stages in the east of Hunan Province. LVR, Loropetalum chinense-Vaccinium bracteatum-Rhododendron mariesii scrub-grass-land; LCQ, Loropetalum chinense-Cunninghamia lanceolata-Quercus fabri shrubbery; PLL, Pinus massoniana-Lithocarpus glaber-Loropetalum chinense coniferous-broad leaved mixed forest; LAG, Lithocarpus glaber-Cleyera japonica-Cyclobalanopsis glauca evergreen broad-leaved forest. Different letters indicate significant differences among different vegetation restoration stages in the same soil layer at the same time of incubation $(p<$ $0.05)$.

从图2可以看出，同一植被恢复阶段，同一培养 时间SOC矿化速率均随土层深度增加而递减，且 0-10 cm土层显著高于其他 3 个土层 $(p<0.05)$, 表明 表土层比深土层积累了更多的可供微生物利用的 $\mathrm{C}$ 。

\subsection{SOC的累积矿化量}

如图3所示, 同一土层 $C_{\mathrm{m}}$ 均随着植被恢复而增 加, 且不同植被恢复阶段差异显著 $(p<0.05)$ 。 $0-10$ $\mathrm{cm}$ 土层, LAG显著高于LVR、LCQ、PLL $(p<0.05)$, 分别高出 $716.31 \% 、 112.38 \% 、 101.01 \%$; LCQ、PLL 与LVR差异显著 $(p<0.05)$, 但LCQ与PLL差异不显 著 $(p>0.05)$ 。 10-20、20-30、30-40 cm 土层, LAG 与LVR、LCQ、PLL之间, PLL与LVR之间差异显著 $(p<0.05)$, 其中LAG比LVR、LCQ、PLL分别高出 $359.06 \%-515.25 \%$ 、 $125.56 \%-232.61 \%$ 、 $94.40 \%-$
$105.74 \%$ ，而LCQ与LVR、PLL差异不显著 $(p>0.05)$ 。 表明植被恢复显著影响 $C_{\mathrm{m}}$, 但影响程度随土层深度 增加而下降。

从图 3 可以看出, 各植被恢复阶段 $C_{\mathrm{m}}$ 也受土壤 深度的影响，均随土层深度增加而递减，且0-10 cm 土层与其他 3 个土层差异显著 $(p<0.05)$ 。

\subsection{SOC的矿化率}

由图4可知，不同植被恢复阶段0-10、10-20、 20-30、30-40 cm土层 $C_{\mathrm{m}} / \mathrm{SOC}$ 分别在 $2.13 \%-4.99 \%$ 、 $3.42 \%-4.18 \% 、 4.05 \%-4.64 \% 、 4.02 \%-5.64 \%$ 之间，随 着植被恢复, $C_{\mathrm{m}} / \mathrm{SOC}$ 的变化因土层不同而异。0-10 $\mathrm{cm}$ 土层, $C_{\mathrm{m}} / \mathrm{SOC}$ 随着植被恢复先增加后减少, 其中 LVR显著低于LCQ、PLL、LAG $(p<0.05)$, 而LCQ、 PLL、LAG两两间差异不显著 $(p>0.05) ; 10-20$ 、 
表3 湖南东部不同植被恢复阶段土壤有机碳矿化速率拟合

Table 3 Fitting of soil organic carbon (SOC) mineralization rate with incubation time using the reciprocal equations at different restoration stages in the east of Hunan Province

\begin{tabular}{|c|c|c|c|c|c|c|c|c|c|c|c|}
\hline $\begin{array}{l}\text { 土层深度 } \\
\text { Soil layer } \\
(\mathrm{cm})\end{array}$ & $\begin{array}{l}\text { 恢复阶段 } \\
\text { Restoration } \\
\text { stages }\end{array}$ & $\begin{array}{c}\text { 回归方程 } \\
\text { Regression equation }\end{array}$ & $R^{2}$ & $F$ & $p$ & \begin{tabular}{||l} 
土层深度 \\
Soil layer \\
$(\mathrm{cm})$
\end{tabular} & $\begin{array}{l}\text { 恢复阶段 } \\
\text { Restoration } \\
\text { stages }\end{array}$ & $\begin{array}{c}\text { 回归方程 } \\
\text { Regression equation }\end{array}$ & $R^{2}$ & $F$ & $p$ \\
\hline \multirow[t]{4}{*}{$0-10$} & LVR & $y=0.023 / x+0.002$ & 0.901 & 100.517 & 0 & \multirow[t]{4}{*}{$20-30$} & LVR & $y=0.018 / x+0.000$ & 0.866 & 71.259 & 0 \\
\hline & LCQ & $y=0.053 / x+0.008$ & 0.970 & 356.194 & 0 & & LCQ & $y=0.021 / x+0.002$ & 0.945 & 187.261 & 0 \\
\hline & PLL & $y=0.056 / x+0.009$ & 0.985 & 747.054 & 0 & & PLL & $y=0.027 / x+0.002$ & 0.982 & 602.893 & 0 \\
\hline & LAG & $y=0.121 / x+0.018$ & 0.978 & 496.637 & 0 & & LAG & $y=0.033 / x+0.005$ & 0.987 & 821.403 & 0 \\
\hline \multirow[t]{4}{*}{$10-20$} & LVR & $y=0.022 / x+0.001$ & 0.918 & 123.038 & 0 & \multirow[t]{4}{*}{$30-40$} & LVR & $y=0.018 / x-1.878 \mathrm{E}-6$ & 0.875 & 76.822 & 0 \\
\hline & LCQ & $y=0.026 / x+0.002$ & 0.979 & 504.574 & 0 & & LCQ & $y=0.018 / x+0.001$ & 0.886 & 85.189 & 0 \\
\hline & PLL & $y=0.029 / x+0.003$ & 0.976 & 455.176 & 0 & & PLL & $y=0.026 / x+0.002$ & 0.967 & 318.004 & 0 \\
\hline & LAG & $y=0.039 / x+0.006$ & 0.949 & 203.566 & 0 & & LAG & $y=0.036 / x+0.004$ & 0.954 & 228.325 & 0 \\
\hline
\end{tabular}

LVR, 聯木-南烛-杜鹃灌草丛; LCQ, 㶌木-杉木-白栎灌木林; PLL, 马尾松-柯-㶌木针阔混交林; LAG, 柯-红淡比-青冈常绿阔叶林。 $y$ 为土壤有机碳矿化 速率, $x$ 为培养时间。

LVR, Loropetalum chinense-Vaccinium bracteatum-Rhododendron mariesii scrub-grass-land; LCQ, Loropetalum chinense-Cunninghamia lanceolata-Quercus fabri shrubbery; PLL, Pinus massoniana-Lithocarpus glaber-Loropetalum chinense coniferous-broad leaved mixed forest; LAG, Lithocarpus glaber-Cleyera japonica-Cyclobalanopsis glauca evergreen broad-leaved forest. $y$ stands for SOC mineralization rate, $x$ stands for incubation time.

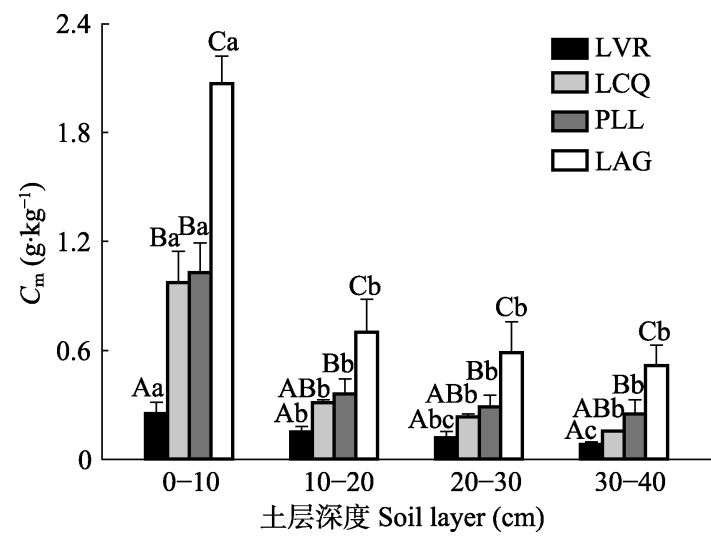

图 3 湖南东部不同植被恢复阶段土壤有机碳累积矿化量 $(\mathrm{Cm})$ (平均值+标准偏差)。LVR，聯木-南烛-杜鹃灌草从; LCQ, 綝木-杉木-白栎灌木林; PLL，马尾松-柯-聯木针阔混交林; LAG，柯-红淡比-青冈常绿阔叶林。不同大写字母表示同一土 层不同植被恢复阶段之间差异显著 $(p<0.05)$, 不同小写字母 表示同一植被恢复阶段不同土层之间差异显著 $(p<0.05)$ 。

Fig. 3 Soil organic carbon cumulative mineralization $\left(C_{\mathrm{m}}\right)$ at different vegetation restoration stages in the east of Hunan Province (mean $+S D)$. LVR, Loropetalum chinense-Vaccinium bracteatum-Rhododendron mariesii scrub-grass-land; LCQ, Loropetalum chinense-Cunninghamia lanceolata-Quercus fabri shrubbery; PLL, Pinus massoniana-Lithocarpus glaber-Loropetalum chinense coniferous-broad leaved mixed forest; LAG, Lithocarpus glaber-Cleyera japonica-Cyclobalanopsis glauca evergreen broad-leaved forest. Different capital letters represent significant differences among different vegetation restoration stages in the same soil layer $(p<0.05)$, and different lower letters indicate significant differences among different soil layers at the same vegetation restoration stage $(p<0.05)$.

20-30、30-40 cm 土层，不同植被恢复阶段之间 $C_{\mathrm{m}} / \mathrm{SOC}$ 差异不显著 $(p>0.05)$, 但总体上呈现出随 着植被恢复而下降趋势。表明随着植被恢复, $C_{\mathrm{m}}$ 和

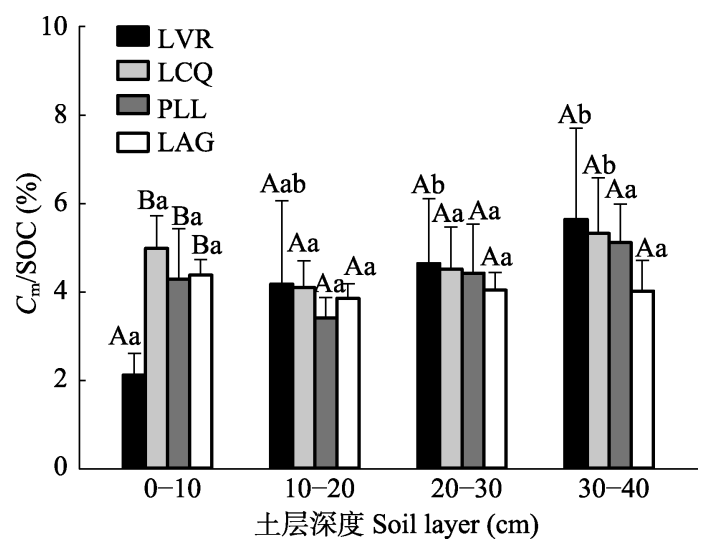

图 4 湖南东部不同植被恢复阶段土壤有机碳矿化率 $\left(C_{\mathrm{m}} / \mathrm{SOC}\right)$ (平均值+标准偏差)。LVR，聯木-南烛-杜鹃灌草丛; LCQ, 聯木-杉木-白柇灌木林; PLL，马尾松-柯-聯木针阔混交 林; LAG，柯-红淡比-青冈常绿阔叶林。不同大写字母表示同一 土层不同植被恢复阶段之间差异显著 $(p<0.05)$, 不同小写字 母表示同一植被恢复阶段不同土层之间差异显著 $(p<0.05)$ 。

Fig. 4 The percentage of soil organic carbon cumulative mineralization to soil organic carbon content $\left(C_{\mathrm{m}} / \mathrm{SOC}\right)$ at different vegetation restoration stages in the east of Hunan Province $($ mean $+S D)$. LVR, Loropetalum chinense-Vaccinium bracteatum-Rhododendron mariesii scrub-grass-land; LCQ, Loropetalum chinense-Cunninghamia lanceolata-Quercus fabri shrubbery; PLL, Pinus massoniana-Lithocarpus glaber-Loropetalum chinense coniferous-broad leaved mixed forest; LAG, Lithocarpus glaber-Cleyera japonica-Cyclobalanopsis glauca evergreen broad-leaved forest. Different capital letters represent significant differences among different vegetation restoration stages in the same soil layer $(p<0.05)$, and different lower letters indicate significant differences among different soil layers at the same vegetation restoration stage $(p<0.05)$.

SOC含量具有不同的变化幅度。

从图4可以看出, LVR、LCQ、PLL的 $C_{\mathrm{m}} / \mathrm{SOC}$ 大 致上均随土层深度增加而增加，其中LVR、LCQ深 
土层显著高于表土层 $(p<0.05)$; 而 $\mathrm{LAG}$ 的 $C_{\mathrm{m}} / \mathrm{SOC}$ 基本上随着土层深度增加而下降，但不同土层两两 之间差异不显著 $(p>0.05)$ 。

\subsection{SOC矿化与植被因子、土壤因子的相关性}

Pearson相关性分析结果(表4, 表5)表明, $C_{\mathrm{m}}$ 与 植物多样性、地上部分生物量、根系生物量、调落 物层 $\mathrm{N} 、 \mathrm{P}$ 含量、土壤 $<0.002 \mathrm{~mm}$ 黏粒百分含量、土 壤 $\mathrm{SOC} 、 \mathrm{TN} 、 \mathrm{TP}$ 含量、土壤 $\mathrm{C}: \mathrm{P} 、 \mathrm{~N}: \mathrm{P}$ 呈显著 $(p<0.05)$ 或极显著 $(p<0.01)$ 正相关关系, 与调落物层 $\mathrm{N}: \mathrm{P}$ 、土 壤 $\mathrm{pH}$ 值呈极显著 $(p<0.01)$ 负相关关系，与调落物层 现存量、C含量、木质素含量、调落物层C:N、C:P、 $\mathrm{N}: \mathrm{P}$ 、土壤容重、C:N不存在显著的相关关系 $(p>$ $0.05)$ 。表明植被恢复过程中, $C_{\mathrm{m}}$ 的变化是植被因子 与土壤因子综合作用的结果。

如表4、表5所示, $C_{\mathrm{m}} / \mathrm{SOC}$ 仅与土壤 $\mathrm{C}: \mathrm{N}$ 呈显著 $(p$ $<0.05)$ 负相关关系, 而与植被因子、土壤容重、 $\mathrm{pH}$ 值、 $<0.002 \mathrm{~mm}$ 黏粒百分含量、 $\mathrm{C}: \mathrm{P} 、 \mathrm{~N}: \mathrm{P}$ 不存在显 著相关关系 $(p>0.05)$ 。表明植被恢复过程中 $C_{\mathrm{m}} / \mathrm{SOC}$ 主要受土壤 $\mathrm{C}: \mathrm{N}$ 的影响, 植被因子、土壤容重、 $\mathrm{pH}$ 值、 $<0.002 \mathrm{~mm}$ 黏粒百分含量、C:P、N:P对 $C_{\mathrm{m}} / \mathrm{SOC}$ 影响不明显。

\subsection{SOC累积矿化量影响因子的主成分分析}

由于与 $C_{\mathrm{m}} / \mathrm{SOC}$ 相关性显著的因子较少，无法 进行主成分分析。因此, 在这里仅对与 $C_{\mathrm{m}}$ 相关性达 到显著水平的因子(植物多样性、地上部分生物量、 根系生物量、调落物层 $\mathrm{N} 、 \mathrm{P}$ 含量、调落物层 $\mathrm{N}: \mathrm{P}$ 、
土壤 $<0.002 \mathrm{~mm}$ 黏粒百分含量、 $\mathrm{pH}$ 值、 $\mathrm{SOC} 、 \mathrm{TN}$ 、 $\mathrm{TP}$ 含量、土壤 $\mathrm{C}: \mathrm{P} 、 \mathrm{~N}: \mathrm{P})$ 进行主成分分析，提取影响 $C_{\mathrm{m}}$ 的主要因子。从表 6 可知, $C_{\mathrm{m}}$ 影响因子的第 $1 、 2 、$ 3 主成分方差累计贡献率达到 $87.17 \%$, 能反映不同 因子对 $C_{\mathrm{m}}$ 影响效应的大部分信息。第 1 主成分与地 上部分生物量、根系生物量、土壤 $\mathrm{SOC} 、 \mathrm{TN}$ 含量有 较大相关性，方差贡献率达 $61.51 \%$; 第2主成分主 要与土壤TP含量有关，方差贡献率为 $14.97 \%$; 第3 主成分与植物多样性、调落物层P含量相关性较大, 方差贡献率为 $10.69 \%$ 。

\subsection{SOC矿化影响因子的逐步回归分析}

从表7可以看出, 土壤 $\mathrm{TN}$ 含量能够独立解释 $C_{\mathrm{m}}$ 变异的 $96.9 \%$, 其次是根系生物量, 两者合计能够 解释 $C_{\mathrm{m}}$ 变异的 $97.8 \%$ 。 $C_{\mathrm{m}}$ 与土壤 $\mathrm{TN}$ 含量、根系生物 量的多元线性回归方程为: $C_{\mathrm{m}}=0.474$ 土壤 $\mathrm{TN}+$ 0.000006 根系生物量 $+0.290(R=0.991, p<0.01)$ 。土 壤 $\mathrm{C}: \mathrm{N}$ 可解释 $C_{\mathrm{m}} / \mathrm{SOC}$ 变异的 $49.4 \%, C_{\mathrm{m}} / \mathrm{SOC}$ 与土壤 $\mathrm{C}: \mathrm{N}$ 的关系可用线性回归方程: $C_{\mathrm{m}} / \mathrm{SOC}=-0.302$ 土 壤 $\mathrm{C}: \mathrm{N}+8.717(R=0.732, p<0.01)$ 表达。表明植被 恢复过程中, 影响 $C_{\mathrm{m}} 、 C_{\mathrm{m}} / \mathrm{SOC}$ 的主导因子不相同。

\section{3 讨论}

\section{1 植被恢复对SOC矿化速率、 $C_{\mathrm{m}}$ 的影响}

地上植被是 $\mathrm{SOC}$ 的重要来源。随着植物恢复, 群落物种组成结构、地被物层、根系分布及细根数 量与质量(化学组成)以及林下微气候环境不断改变,

表4 土壤有机碳累积矿化量 $\left(C_{\mathrm{m}}\right)$ 、土壤有机碳矿化率 $\left(C_{\mathrm{m}} / \mathrm{SOC}\right)$ 与植被因子的Pearson相关系数

Table 4 Pearson correlation coefficient between soil organic carbon (SOC) cumulative mineralization $\left(C_{\mathrm{m}}\right)$, the percentage of $C_{\mathrm{m}}$ to SOC content $\left(C_{\mathrm{m}} / \mathrm{SOC}\right)$ and vegetation factors, respectively

\begin{tabular}{|c|c|c|c|c|c|c|c|c|c|c|c|}
\hline $\begin{array}{l}\text { 项目 } \\
\text { Item }\end{array}$ & $\begin{array}{c}\text { 植物多样 } \\
\text { 性指数 } \\
\text { Species diver- } \\
\text { sity index }\end{array}$ & $\begin{array}{c}\text { 地上部分 } \\
\text { 生物量 } \\
\text { Aboveground } \\
\text { biomass }\end{array}$ & $\begin{array}{c}\text { 根系 } \\
\text { 生物量 } \\
\text { Root } \\
\text { biomass }\end{array}$ & $\begin{array}{l}\text { 凋落物层 } \\
\text { 现存量 } \\
\text { Existing } \\
\text { biomass in } \\
\text { litter layer }\end{array}$ & $\begin{array}{l}\text { 凋落物层 } \\
\mathrm{C} \text { 含量 } \\
\mathrm{C} \text { concen- } \\
\text { tration in } \\
\text { litter layer }\end{array}$ & $\begin{array}{l}\text { 调落物层 } \\
\mathrm{N} \text { 含量 } \\
\mathrm{N} \text { concen- } \\
\text { tration in } \\
\text { litter layer }\end{array}$ & $\begin{array}{l}\text { 凋落物层 } \\
\mathrm{P} \text { 含量 } \\
\mathrm{P} \text { concen- } \\
\text { tration in } \\
\text { litter layer }\end{array}$ & $\begin{array}{c}\text { 调落物层 } \\
\text { 木质素含量 } \\
\text { Lignin con- } \\
\text { centration in } \\
\text { litter layer }\end{array}$ & $\begin{array}{c}\text { 调落物层 } \\
\text { C:N } \\
\text { The ratio of } \\
\mathrm{C} \text { to } \mathrm{N} \text { in } \\
\text { litter layer }\end{array}$ & $\begin{array}{c}\text { 调落物层 } \\
\text { C:P } \\
\text { The ratio of } \\
\mathrm{C} \text { to } \mathrm{P} \text { in } \\
\text { litter layer }\end{array}$ & $\begin{array}{c}\text { 凋落物层 } \\
\mathrm{N}: \mathrm{P} \\
\text { The ratio of } \\
\mathrm{N} \text { to } \mathrm{P} \text { in } \\
\text { litter layer }\end{array}$ \\
\hline$C_{\mathrm{m}}$ & $0.625^{*}$ & $0.818^{* *}$ & $0.897^{* *}$ & 0.539 & 0.269 & $0.669^{*}$ & $0.640^{*}$ & 0.397 & 0.098 & -0.287 & -0.490 \\
\hline$C_{\mathrm{m}} / \mathrm{SOC}$ & -0.057 & -0.150 & -0.082 & -0.075 & 0.051 & 0.171 & 0.137 & 0.016 & 0.010 & -0.027 & -0.155 \\
\hline
\end{tabular}

$n=13, * p<0.05, * * p<0.01$ 。

表5 土壤有机碳 $(\mathrm{SOC})$ 累积矿化量 $\left(C_{\mathrm{m}}\right)$ 、土壤有机碳矿化率 $\left(C_{\mathrm{m}} / \mathrm{SOC}\right)$ 与土壤因子的Pearson相关系数

Table 5 Pearson correlation coefficient between soil organic carbon (SOC) cumulative mineralization $\left(C_{\mathrm{m}}\right)$, the percentage of $C_{\mathrm{m}}$ to SOC content $\left(C_{\mathrm{m}} / \mathrm{SOC}\right)$ and soil factors, respectively

\begin{tabular}{|c|c|c|c|c|c|c|c|c|c|}
\hline 项目 Item & $\begin{array}{c}\text { 容重 } \\
\text { Bulk density }\end{array}$ & $\begin{array}{l}\quad<0.002 \mathrm{~mm} \text { 黏粒百分含量 } \\
\text { Soil clay percentage of }<0.002 \mathrm{~mm}\end{array}$ & $\mathrm{pH}$ & SOC & $\mathrm{TN}$ & $\mathrm{TP}$ & $\mathrm{C}: \mathrm{N}$ & $C: P$ & $\mathrm{~N}: \mathrm{P}$ \\
\hline$C_{\mathrm{m}}$ & -0.312 & $0.774^{* *}$ & $-0.734^{* *}$ & $0.971^{* *}$ & $0.986^{* *}$ & $0.595^{*}$ & -0.315 & $0.653^{*}$ & $0.738^{* *}$ \\
\hline$C_{\mathrm{m}} / \mathrm{SOC}$ & 0.154 & -0.203 & 0.323 & -0.320 & -0.223 & -0.172 & $-0.732^{* *}$ & -0.268 & -0.096 \\
\hline
\end{tabular}

$\mathrm{C}: \mathrm{N}$, 土壤碳氮比; $\mathrm{C}: \mathrm{P}$, 土壤碳磷比; $\mathrm{N}: \mathrm{P}$, 土壤氮磷比; $\mathrm{TN}$, 土壤全氮含量; TP, 土壤全磷含量。 $n=13, * p<0.05, * * p<0.01$ 。

$\mathrm{C}: \mathrm{N}$, ratio of carbon to nitrogen in soil; $\mathrm{C}: \mathrm{P}$, ratio of carbon to phosphorus in soil; N:P, ratio of nitrogen to phosphorus in soil; TN, soil total nitrogen concentration; TP, soil total phosphorus concentration. $n=13, * p<0.05, * * p<0.01$. 
表6 植被因子和土壤因子主成分载荷矩阵、特征值及贡献率

Table 6 The principle component loading matrix, eigenvalue and contribution rate for vegetation and soil factors

\begin{tabular}{|c|c|c|c|c|c|c|c|}
\hline \multirow[t]{2}{*}{ 因子 Factor } & \multicolumn{3}{|c|}{ 主成分 Component } & \multirow[t]{2}{*}{ 因子 Factor } & \multicolumn{3}{|c|}{ 主成分 Component } \\
\hline & 1 & 2 & 3 & & 1 & 2 & 3 \\
\hline 植物多样性指数 Species diversity index & 0.639 & -0.103 & 0.515 & $\begin{array}{l}\text { 土壤有机碳含量 } \\
\text { Soil organic carbon concentration }\end{array}$ & 0.947 & -0.142 & -0.084 \\
\hline 地上部分生物量 Aboveground biomass & 0.883 & -0.005 & -0.410 & $\begin{array}{l}\text { 土壤全氮含量 } \\
\text { Soil total nitrogen concentration }\end{array}$ & 0.951 & -0.158 & 0.043 \\
\hline 根系生物量 Root biomass & 0.951 & 0.003 & -0.212 & $\begin{array}{l}\text { 土壤全磷含量 } \\
\text { Soil total phosphorus concentration }\end{array}$ & 0.536 & -0.823 & -0.064 \\
\hline $\begin{array}{l}\text { 凋落物层N含量 } \\
\text { Nitrogen concentration in litter layer }\end{array}$ & 0.763 & 0.320 & 0.094 & 土壤碳磷比 Soil C:P & 0.697 & 0.675 & -0.111 \\
\hline $\begin{array}{l}\text { 凋落物层P含量 } \\
\text { Phosphorus concentration in litter layer }\end{array}$ & 0.651 & -0.245 & 0.512 & 土壤氮磷比 Soil N:P & 0.767 & 0.613 & 0.073 \\
\hline $\begin{array}{l}<0.002 \mathrm{~mm} \text { 黏粒百分含量 } \\
\text { Soil clay percentage of }<0.002 \mathrm{~mm}\end{array}$ & 0.711 & -0.040 & 0.473 & 贡献率 Contribution rate (\%) & 61.511 & 14.966 & 10.687 \\
\hline 土壤pH值 Soil $\mathrm{pH}$ value & -0.782 & 0.261 & -0.752 & $\begin{array}{l}\text { 累积贡献率 } \\
\text { Accumulative contribution rate }(\%)\end{array}$ & 61.511 & 76.477 & 87.165 \\
\hline
\end{tabular}

表7 土壤有机碳累积矿化量 $\left(C_{\mathrm{m}}\right)$ 和土壤有机碳矿化率 $\left(C_{\mathrm{m}} / \mathrm{SOC}\right)$ 影响因子的逐步回归分析

Table 7 The stepwise regression analysis for main influencing factors of soil organic carbon (SOC) cumulative mineralization $\left(C_{\mathrm{m}}\right)$ and the percentage of $C_{\mathrm{m}}$ to SOC content $\left(C_{\mathrm{m}} / \mathrm{SOC}\right)$

\begin{tabular}{|c|c|c|c|c|c|c|c|}
\hline 项目 Item & $\begin{array}{l}\text { 模型 } \\
\text { Model }\end{array}$ & $\begin{array}{l}\text { 变量 } \\
\text { Variable }\end{array}$ & 回归方程 Regression equation & $\begin{array}{c}\text { 多元相关系数 } \\
\text { Multiple correlation coefficient }(R)\end{array}$ & $\begin{array}{l}\text { 调整判定系数 } \\
\text { Adjust } R^{2}\end{array}$ & $F$ & $P$ \\
\hline \multirow[t]{2}{*}{$C_{\mathrm{m}}$} & 1 & $\mathrm{TN}$ & $C_{\mathrm{m}}=0.572 \mathrm{TN}+0.250$ & 0.986 & 0.969 & 380.581 & 0.000 \\
\hline & 2 & $\mathrm{RB}$ & $C_{\mathrm{m}}=0.474 \mathrm{TN}+0.000006 \mathrm{RB}+0.290$ & 0.991 & 0.978 & 273.558 & 0.000 \\
\hline$C_{\mathrm{m}} / \mathrm{SOC}$ & 1 & Soil C:N & $C_{\mathrm{m}} / \mathrm{SOC}=-0.302 \mathrm{C}: \mathrm{N}+8.717$ & 0.732 & 0.494 & 12.700 & 0.004 \\
\hline
\end{tabular}

$n=13$ 。 $\mathrm{TN}$, 土壤全氮含量; RB, 根系生物量; Soil C:N, 土壤碳氮比。

$\mathrm{TN}$, soil total nitrogen concentration; RB, Root biomass; Soil C:N, ratio of carbon to nitrogen in soil.

导致土壤 $\mathrm{C}$ 数量及质量和土壤微生物群落组成结构 及其活性的差异, 从而影响 SOC矿化过程(Priha \& Grayston, 2001; 张玲等, 2017)。进而影响土壤与大 气之间的 $\mathrm{CO}_{2}$ 交换数量与过程。研究表明, 植被恢复 显著提高SOC矿化速率(张浩等, 2016)和 $C_{\mathrm{m}}$ (黄宗胜 等, 2012)。根系生物量较高的植物群落往往具有较 高的土壤呼吸速率(Schaefer et al., 2009)。调落物质 量是影响SOC矿化的重要因素(周玉燕等, 2011), SOC矿化速率与调落物 N含量呈正相关关系(Iyamuremye et al., 2000)。本研究中, SOC矿化速率和 $C_{\mathrm{m}}$ 均 随着植被恢复逐渐提高, 且同一土层不同植被恢复 阶段差异显著，表明随着植被恢复，SOC含量增加、 质量改善, 微生物量增多、分解活动增强(黄宗胜等, 2012)。究其原因可能是: (1)随着植被恢复, 植物种 类增加, 群落组成结构趋于复杂化, 植被覆盖度明 显提高(辜翔等, 2018), 调落物量和根系生物量显著 增加(表1), 调落物质量(C:N、C:P、N:P下降)得到显 著改善(表1), 不仅增加SOC输入量, 而且提高了土 壤微生物底物的可利用性, 促进土壤微生物生长和 活性, 有利于 $\mathrm{SOC}$ 矿化和 $C_{\mathrm{m}}$ 的积累。相关性分析也
表明, 植物多样性、地上部分生物量、根系生物量、 调落物质量(调落物 $\mathrm{N} 、 \mathrm{P}$ 含量、 $\mathrm{N}: \mathrm{P}$ ) 显著影响着 $C_{\mathrm{m}}$ (表4)。(2)随着植被恢复, 土壤质地和养分含量的变 化对SOC矿化产生显著的影响(张玲等, 2017)。其中, SOC 含量是影响 SOC 矿化的关键因子 (Kuzyakov, 2001), SOC含量越高, 微生物分解代谢活动越旺盛, SOC矿化速率越快(杨开军等, 2017), $C_{\mathrm{m}}$ 也越高(张 浩等, 2016)。土壤 $\mathrm{N} 、 \mathrm{P}$ 是植物生长的重要养分, 也 是微生物活动的主要营养、能量来源, 与 $\mathrm{SOC}$ 矿化 速率呈显著正相关关系(Riffaldi et al., 1996), 土壤 $\mathrm{pH}$ 值也是影响微生物数量和活性的重要因子, $\mathrm{pH}$ 值 偏高对SOC矿化产生消极影响(李隽永等, 2018)。本 研究中, 随着植被恢复, 土壤酸性增强( $\mathrm{pH}$ 值下降), SOC、TN、TP含量增高(表2), SOC矿化速率提高(图 2), $C_{\mathrm{m}}$ 随着SOC、TN、TP含量、C:P、N:P增加而增 加(表2, 表5)。表明随着植被恢复, $C_{\mathrm{m}}$ 不仅受植物多 样性、地上部分生物量、根系生物量、调落物 $\mathrm{N} 、 \mathrm{P}$ 含量、 $\mathrm{N}$ : $\mathrm{P}$ 等植被因子影响, 而且与土壤 $\mathrm{pH}$ 值、SOC、 $\mathrm{TN} 、 \mathrm{TP}$ 含量、C:P、N:P等土壤因子密切相关。此 外, 本研究中, 土壤 $\mathrm{TN}$ 含量、根系生物量可解释 $C_{\mathrm{m}}$ 
变异的 $97.8 \%$, 其中土壤 $\mathrm{TN}$ 含量可独立解释 $C_{\mathrm{m}}$ 变异 的 $96.9 \%$, 表明在植被恢复过程中, 土壤 $\mathrm{TN}$ 含量、根 系生物量的变化是影响SOC滞留的重要因素。

本研究中, 4种植被恢复阶段 SOC矿化速率和 $C_{\mathrm{m}}$ 均随土层深度增加而递减, 且0 $-10 \mathrm{~cm}$ 土层显著 高于其他 3 个土层 $(p<0.05)$ 。其主要原因是: 调落物 和根系是 $\mathrm{SOC}$ 矿化底物基质的主要来源, 调落物分 解产物、根系分泌物首先进入土壤表层, 使表土层 SOC、养分含量较高、土壤微生物和酶活性较强, $\mathrm{SOC}$ 矿化速率较快, $C_{\mathrm{m}}$ 较大; 而深土层 $\mathrm{SOC}$ 、养分含 量较低, 微生物可利用底物有效性较低, 导致SOC 矿化作用较弱, SOC矿化速率较慢, $C_{\mathrm{m}}$ 较小(宋媛等, 2013; 杨开军等, 2017)。同时, 不同恢复阶段植被深 土层发育于同一母质, 受地上植被调落物、根系的 影响较小, 因而随着土壤深度增加, 各植被恢复阶 段之间SOC矿化速率、 $C_{\mathrm{m}}$ 的差异减弱。

\section{2 植被恢复对SOC矿化率的影响}

植被恢复过程中, SOC含量及其矿化速率都在 变化, 但变化幅度不同, 这些差异体现在 $C_{\mathrm{m}} / \mathrm{SOC}$ 的 变化上。实际上, $C_{\mathrm{m}} / \mathrm{SOC}$ 是从 $\mathrm{SOC}$ 含量角度来反映 $\mathrm{SOC}$ 矿化速率, 在一定程度上可以反映土壤的固 $\mathrm{C}$ 能力和 $\mathrm{SOC}$ 的稳定性。该值越小, 土壤固 $\mathrm{C}$ 能力越强, SOC稳定性越高; 反之, 土壤固 $C$ 能力越弱, SOC稳 定性越低(严毅萍等, 2012; 李杨梅等, 2017)。研究表 明, SOC含量随着植被恢复而显著增加(㙜翔等, 2018)。本研究中, $C_{\mathrm{m}}$ 也随着植被恢复而增加, 尽管 $C_{\mathrm{m}} / \mathrm{SOC}$ 在不同植被恢复阶段之间差异不显著, 但 总体上还是呈现出随着植被恢复而下降的趋势, 表 明 $\mathrm{SOC}$ 的增加幅度大于 $C_{\mathrm{m}}$, 因此在一定程度上, 植 被恢复可增强土壤的固 $\mathrm{C}$ 能力和提高 $\mathrm{SOC}$ 的稳定 性。另一方面, 也表明了用 $C_{\mathrm{m}} / \mathrm{SOC}$ 表征SOC矿化速 率时, 植被对其的影响程度下降。究其原因可能是: 随着植被恢复, 输入土壤的有机质增加使得 SOC含 量和 $C_{\mathrm{m}}$ 增加, 但也由于部分易分解有机 $C$ 转变为稳 定有机C而使得矿化速率的增加幅度在一定程度上 下降, 因而 $\mathrm{SOC}$ 的增加幅度大于 $C_{\mathrm{m}}$ (吴建国等, 2004)。在0-10 cm 土层, LVR的 $C_{\mathrm{m}} / \mathrm{SOC}$ 显著低于其 他 3 种植被恢复阶段, 主要因为: (1) LVR植物种类 少(啈翔等, 2018), 且组成结构简单, 生物量低(表1), SOC输入量少, 不利于 SOC 的储存和稳定组分的形 成(吴建国等, 2002; 辜翔等, 2018); (2) LVR地表大 面积裸露, 抗风化能力较弱, 土壤养分流失严重(表
2), 不仅导致土壤固 $C$ 能力下降, 还使土壤中较为稳 定的 SOC 转变为易分解的有机C, 从而增加 SOC 矿 化速率和 $C_{\mathrm{m}}$ (吴建国等, 2004)。这也进一步说明地 上植被遭到破坏后, 土壤SOC分解加快、稳定性下 降, 不利于SOC的固持。在0-10、10-20 cm土层, PLL 的 $C_{\mathrm{m}} / \mathrm{SOC}$ 低于LAG, 表明PLL在0-10、10-20 cm土 层中可被微生物利用、矿化分解的SOC含量低于 LAG, 可能是由于PLL地表调落物层以硬质马尾松 针叶为主, 含有较多油脂, 难以分解, 而LAG地表 调落物层以阔叶为主, 质量高、难分解物质较少, 导 致PLL的SOC活性低于LAG (辜翔等, 2013; 孙伟军 等, 2013); 同时也由于调落物所形成的有机C最先 进入土壤表层, 使得PLL的0-10、10-20 cm土层难以 被微生物利用的SOC较多。

研究表明, 在缺 $\mathrm{N}$ 条件下, 土壤 $\mathrm{C}: \mathrm{N}$ 高, 普通腐 生微生物(如细菌、真菌等)活性提高、繁殖快, 矿化 速率提高, 产生大量的 $\mathrm{CO}_{2}, \mathrm{C}_{\mathrm{m}} / \mathrm{SOC}$ 增加(刘朔等, 2008 ); 但也有研究发现, 土壤 $\mathrm{C}: \mathrm{N}$ 高, 微生物生长 受到 N限制, 微生物活性下降, SOC矿化速率和 $C_{\mathrm{m}}$ 较低, 使得 $\mathrm{SOC}$ 中被矿化C下降, 有利于 $\mathrm{SOC}$ 的储 存(Xu et al., 2016)。本研究中, 土壤 $\mathrm{C}: \mathrm{N}$ 对 $C_{\mathrm{m}} / \mathrm{SOC}$ 影响最显著, 且 $C_{\mathrm{m}} / \mathrm{SOC}$ 随着土壤 $\mathrm{C}: \mathrm{N}$ 增加而下降 (表6), 其原因可能是: 随着植被恢复, SOC增长幅 度明显高于 $\mathrm{TN}$ (表2), 土壤 $\mathrm{C}: \mathrm{N}$ 增大, 在一定程度上 有利于SOC的储存。

研究表明, 同一植被不同土层 $C_{\mathrm{m}} / \mathrm{SOC}$ 不同, 不 同恢复年限马尾松林深土层 $C_{\mathrm{m}} / \mathrm{SOC}$ 显著高于表土 层(张浩等, 2016)。本研究中, LVR、LCQ、PLL的 $C_{\mathrm{m}} / \mathrm{SOC}$ 随着土层深度增加大致上呈增大的趋势, 而 $\mathrm{LAG}$ 的 $C_{\mathrm{m}} / \mathrm{SOC}$ 呈降低的趋势(图4)。可能是由于 归还土壤的有机质含量随着土层加深而减少, 微生 物活性减弱, SOC含量(表2)、 $C_{\mathrm{m}}$ (图3)均呈下降趋势, 植被恢复早期(LVR)和中期阶段(LCQ、PLL) SOC含 量下降幅度大于 $C_{\mathrm{m}}$, 而植被恢复后期(LAG) SOC含 量下降幅度小于 $C_{\mathrm{m}}$ 。表明植被恢复早期(LVR)和中 期阶段(LCQ、PLL), SOC稳定性随土层加深而减弱, 植被恢复后期(LAG), SOC稳定性随土层加深而增 强, 植被恢复过程中, 与表土层相比, 深土层 SOC 稳定性提高可能需要一个更长的过程。

\section{4 结论}

(1)不同植被恢复阶段 SOC矿化随时间的变化 
均具有明显的阶段性, 即培养初期, SOC矿化速率 较高, 之后逐渐下降并趋于相对平稳状态, 且这种 阶段性特征并不随着植被恢复而有明显的改变。

(2)随着植被恢复, $\mathrm{SOC}$ 矿化速率和 $C_{\mathrm{m}}$ 均显著增 加, $C_{\mathrm{m}} / \mathrm{SOC}$ 总体上呈下降趋势, 表明植被恢复显著 影响 SOC 矿化过程, 有利于土壤固 $\mathrm{C}$, 但深土层土 壤 $\mathrm{C}$ 库恢复程度明显滞后于表土层, 深土层土壤固 $\mathrm{C}$ 能力和 $\mathrm{SOC}$ 稳定性的提高需要一个较长的过程。

(3)植被恢复过程中, 土壤 $\mathrm{TN}$ 含量和根系生物 量是调控 $C_{\mathrm{m}}$ 的最主要因子, 而土壤 $\mathrm{C}: \mathrm{N}$ 是调控 $C_{\mathrm{m}} / \mathrm{SOC}$ 的最主要因子。此外, 其他植物因子(如植物 多样性、地上部分生物量、根系生物量、调落物 $\mathrm{N}$ 、 $\mathrm{P}$ 含量和 $\mathrm{N}: \mathrm{P}$ ) 和土壤因子(如土壤 $\mathrm{pH}$ 值、SOC、TN、 TP含量和C:P、N:P)也是导致不同植被恢复阶段 $C_{\mathrm{m}}$ 差异的原因。可见, 中亚热带地区植被恢复过程中 土壤与大气 $\mathrm{CO}_{2}$ 交换过程受土壤养分含量和根系生 物量影响较大, 植被恢复有利于促进土壤固 $\mathrm{C}$ 。

致谢 感谢中南林业科技大学生命科学与技术学院 生态教研室项文化教授、雷丕锋副教授在论文修改 过程中给予的帮助。感谢中南林业科技大学引进高 层次人才科研启动基金项目 (2014YJ019); 中南林 业科技大学研究生科技创新基金项目(CX2015A06) 的资助。

\section{参考文献}

Craine JM, Fierer N, Mclauchlan KK (2010). Widespread coupling between the rate and temperature sensitivity of organic matter decay. Nature Geoscience, 3, 854-857.

Cui J, Zhang RJ, Bu NS, Zhang HB, Tang BP, Li ZL, Jiang LF, Chen JK, Fang CM (2013). Changes in soil carbon sequestration and soil respiration following afforestation on paddy fields in north subtropical China. Journal of Plant Ecology, 6, 240-252.

Fan YX, Yang YS, Guo JF, Yang ZJ, Chen GS, Xie JS, Zhong $\mathrm{XJ}, \mathrm{Xu}$ LL (2014). Changes in soil respiration and its temperature sensitivity at different successional stages of evergreen broadleaved forests in mid-subtropical China. Chinese Journal of Plant Ecology, 38, 1155-1165. [范跃 新, 杨玉盛, 郭剑芬, 杨智杰, 陈光水, 谢锦升, 钟小 剑, 徐玲琳 (2014). 中亚热带常绿阔叶林不同演替阶段 土壤呼吸及其温度敏感性的变化. 植物生态学报, 38 , 1155-1165.]

Gu X, Fang X, Xiang WH, Li SL, Sun WJ (2013). Soil organic carbon and mineralizable organic carbon in four subtropical forests in hilly region of central Hunan Province, China. Chinese Journal of Ecology, 32, 2687-2694. [喜翔, 方
方晰, 项文化, 李胜蓝, 孙伟军 (2013). 湘中丘陵区4种 森林类型土壤有机碳和可矿化有机碳的比较. 生态学 杂志, 32, 2687-2694.]

Gu X, Zhang SJ, Liu ZD, Li LD, Chen JL, Wang LF, Fang X (2018). Effects of vegetation restoration on soil organic carbon concentration and density in the mid-subtropical region of China. Chinese Journal of Plant Ecology, 42, 595-608. [幸翔, 张仕吉, 刘兆丹, 李雷达, 陈金磊, 王 留芳, 方晰 (2018). 中亚热带植被恢复对土壤有机碳含 量、碳密度的影响. 植物生态学报, 42, 595-608.]

Hu YL, Zeng DH, Fan ZP, Ai GY (2007). Effects of degraded sandy grassland afforestation on soil quality in semiarid area of Northern China. Chinese Journal of Applied Ecology, 18, 2391-2397. [胡亚林, 曾德慧, 范志平, 艾桂艳 (2007). 半干旱区沙质退化草地造林对土壤质量的影响. 应用生态学报, 18, 2391-2397.]

Huang ZS, Yu LF, Fu YH (2012). Characteristics of soil mineralizable carbon pool in natural restoration process of karst forest vegetation. Chinese Journal of Applied Ecology, 23, 2165-2170. [黄宗胜, 喻理飞, 符裕红 (2012). 喀斯特 森林植被自然恢复过程中土壤可矿化碳库特征. 应用 生态学报, 23, 2165-2170.]

Iyamuremye F, Gewin V, Dick RP, Diack M, Sene M, Badiane A (2000). Carbon, nitrogen and phosphorus mineralization potential of native agroforestry plant residues in soils of Senegal. Arid Soil Research and Rehabilitation, 14, 359-371.

Kuzyakov Y (2011). How to link soil $\mathrm{C}$ pools with $\mathrm{CO}_{2}$ fluxes. Biogeosciences, 8, 1523-1537.

Li JY, Dou XL, Hu YH, Gan DX, Li F (2018). Variation in soil organic carbon mineralization under various land cover types in urban areas. Acta Ecologica Sinica, 38, 112-121. [李隽永, 窦晓琳, 胡印红, 甘德欣, 李锋 (2018). 城市 不同地表覆盖类型下土壤有机碳矿化的差异. 生态学 报, 38, 112-121.]

Li Y, Xu M, Sun OJ, Cui W (2004). Effects of root and litter exclusion on soil $\mathrm{CO}_{2}$ efflux and microbial biomass in wet tropical forests. Soil Biology \& Biochemistry, 36, 2111-2114.

Li YM, Gong L, Xie LN (2017). Soil organic carbon content and carbon mineralization characteristics under different land use types in Northern Tarim Basin. Bulletin of Soil and Water Conservation, 37(3), 216-221. [李杨梅, 贡璐, 解丽娜 (2017). 塔里木盆地北缘绿洲不同土地利用方 式下土壤有机碳含量及其碳矿化特征. 水土保持通报, 37(3), 216-221.]

Liu S, Yuan WY, Li XW, Rong L, Yang M, Li DH, Wang Q (2008). Soil chemical characteristics and their effects on $\mathrm{C}: \mathrm{N}$ ratio of rhizosphere and non-rizosphere of different herbages in triploid of Populous tomentosa woodland. Reseaech of Soil and Water Conservation, 15(2), 107-110. [刘朔, 袁渭阳, 李贤伟, 荣丽, 杨渺, 李德会, 王巧

www.plant-ecology.com 
(2008). 不同草本层三倍体毛白杨根际与非根际土壤化 学特性及其对 $\mathrm{C} / \mathrm{N}$ 的影响. 水土保持研究, 15(2), 107-110.]

Liu YQ, Wang F, Ke GQ, Wang YY, Guo SM, Fan CF (2011). Effects of converting cultivated land into forest land on the characteristics of soil organic carbon in limestone mountain area in Ruichang, Jiangxi. Chinese Journal of Applied Ecology, 22, 885-890. [刘苑秋, 王芳, 柯国庆, 王迎迎, 郭圣茂, 范承芳 (2011). 江西瑞昌石灰岩山区退耕还林 对土壤有机碳的影响. 应用生态学报, 22, 885-890.]

Milcu A, Heim A, Ellis RJ, Scheu S, Manning P (2011). Identification of general patterns of nutrient and labile carbon control on soil carbon dynamics across a successional gradient. Ecosystems, 14, 710-719.

Priha O, Grayston SJ (2001). Microbial community structure and characteristics of the organic matter in soils under Pinus sylvestris, Picea abies and Betula pendula at two forest sites. Biology \& Fertility of Soils, 33, 17-24.

Qian HY, Pan JJ, Sun B (2013). The relative impact of land use and soil properties on sizes and turnover rates of soil organic carbon pools in subtropical China. Soil Use \& Management, 29, 510-518.

Reza MT, Becker W, Sachsenheimer K, Mumme J (2014). Hydrothermal carbonization (HTC): Near infrared spectroscopy and partial least-squares regression for determination of selective components in HTC solid and liquid products derived from maize silage. Bioresource Technology, 161, 91-101.

Riffaldi R, Saviozzi A, Levi-Minzi R (1996). Carbon mineralization kinetics as influenced by soil properties. Biological \& Fertility of Soils, 22, 293-298.

Ross DJ, Tate KR, Scott NA, Wilde RH, Rodda NJ, Townsend JA (2002). Afforestation of pastures with Pinus radiata influences soil carbon and nitrogen pools and mineralisation and microbial properties. Soil Research, 40, 1303-1318.

Saggar S, Yeates GW, Shepherd TG (2001). Cultivation effects on soil biological properties, microfauna and organic matter dynamics in Eutric Gleysol and Gleyic Luvisol soils in New Zealand. Soil \& Tillage Research, 8, 55-68.

Schaefer DA, Feng WT, Zou XM (2009). Plant carbon inputs and environmental factors strongly affect soil respiration in a subtropical forest of southwestern China. Soil Biology \& Biochemistry, 41, 1000-1007.

Scott-Denton LE, Sparks KL, Monson RK (2003). Spatial and temporal controls of soil respiration rate in a highelevation, subalpine forest. Soil Biology \& Biochemistry, $35,525-534$.

Shao YH, Pan JJ, Sun B (2005). Study of characteristics of soil organic carbon decompositions and carbon pool under different vegetations. Journal of Soil and Water Conservation, 19(3), 24-28. [邵月红, 潘剑君, 孙波 (2005). 不同 森林植被下土壤有机碳的分解特征及碳库研究. 水土
保持学报, 19(3), 24-28.]

Song XZ, Jiang H, Yu SQ, Ma YD, Zhou GM, Dou RP, Guo PP (2009). Litter decomposition of dominant plant species in successional stages in mid-subtropical zone. Chinese Journal of Applied Ecology, 20, 537-542. [宋新章, 江洪, 余树全, 马元丹, 周国模, 窦荣鹏, 郭培培 (2009). 中 亚热带森林群落不同演替阶段优势种调落物分解试验. 应用生态学报, 20, 537-542.]

Song Y, Zhao XZ, Mao ZJ, Sun T, Hou LL (2013). SOC decomposition of four typical broad-leaved Korean pine communities in Xiaoxing'an Mountain. Acta Ecologica Sinica, 33，443-453. [宋媛, 赵溪竹, 毛子军, 孙涛, 侯 玲玲 (2013). 小兴安岭4种典型阔叶红松林土壤有机碳 分解特性. 生态学报, 33, 443-453.]

Sun SQ, Bhatti JS, Jassal RS, Chang SX, Arevalo C, Black TA, Sidders D (2015). Stand age and productivity control soil carbon dioxide efflux and organic carbon dynamics in poplar plantations. Soil Science Society of America Journal, 79, 1638-1649.

Sun WJ, Fang X, Xiang WH, Zhang SJ, Li SL (2013). Active pools of soil organic carbon in subtropical forests at different successional stages in Central Hunan, China. Acta Ecologica Sinica, 33，7765-7773. [孙伟军, 方晰, 项文 化, 张仕吉, 李胜蓝 (2013). 湘中丘陵区不同演替阶段 森林土壤活性有机碳库特征. 生态学报, 33, 7765-7773.]

Wen QX (1984). The Determination Method of Soil Organic Matter. Chinese Agriculture Press, Beijing. 273-284. [文 启孝 (1984). 土壤有机质研究法. 中国农业出版社, 北 京. 273-284.]

Wu JG, Zhang XQ, Wang YH, Xu DY (2002). The effects of land use changes on the distribution of soil organic carbon in physical fraction of soil. Scientia Silvae Science, 38(4), 19-29. [吴建国, 张小全, 王彦辉, 徐德应 (2002). 土地 利用变化对土壤物理组分中有机碳分配的影响. 林业 科学, 38(4), 19-29.]

Wu JG, Zhang XQ, Xu DY (2004). The mineralization of soil organic carbon under different land use in the Liupan Mountains forest zone. Acta Phytoecologica Sinica, 28, 530-538. [吴建国, 张小全, 徐德应 (2004). 六盘山林 区几种土地利用方式对土壤有机碳矿化影响的比较. 植物生态学报, 28, 530-538.]

Wu JH, Pan JJ, Ge XJ, Cao LD, Li BY, Chen X (2015). Mineralization of soil organic carbon and its relationship wih organic carbon fractions under different agriculture land use. Journal of Soil and Water Conservation, 29(6), 178-183. [邬建红, 潘剑君, 葛序娟, 曹罗丹, 李炳亚, 陈昕 (2015). 不同农业利用方式土壤有机碳矿化及其 与有机碳组分的关系. 水土保持学报, 29(6), 178-183.]

Xiang WH, Fang X (2018). Community Structure and Soil Properties in Subtropical Secondary Forests. Science Press, Beijing. [项文化, 方晰 (2018). 亚热带次生林群 落结构与土壤特征. 科学出版社, 北京.] 
Xu X, Shi Z, Li DJ, Rey A, Ruan HH, Craine J, Liang JY, Zhou JZ, Luo YQ (2016). Soil properties control decomposition of soil organic carbon: Results from data-assimilation analysis. Geoderma, 262, 235-242.

Yan YP, Cao JH, Liang Y, Wang P, Wang H (2012). Organic carbon storage and decomposition rate of three subcategories of calcareous soil in karst area. Earth and Environment, 40(2), 219-226. [严毅萍, 曹建华, 梁毅, 王培, 王 宏 (2012). 桂林毛村岩溶区三种亚类石灰土有机碳矿 化研究. 地球与环境, 40(2), 219-226.]

Yang KJ, Yang WQ, He RY, Zhuang LY, Li ZJ, Nie FY, Wang $\mathrm{Z}$, Xu ZF (2017). Soil organic carbon mineralization characteristics of three dominant subalpine forests in western Sichuan, China. China Journal Apply Environment Biology, 23(5), 851-856. [杨开军, 杨万勤, 贺若阳, 庄丽燕, 李志杰, 聂富育, 王壮, 徐振锋 (2017). 川西亚高山3种 典型森林土壤碳矿化特征. 应用与环境生物学报, 23(5), 851-856.]

Zhang H, Lü MK, Jiang J, Pu XT, Wang EX, Qiu X, Xie JS (2016). Effects of vegetation restoration on topsoil and subsoil organic carbon mineralization in red soil erosion area. Journal of Soil and Water Conservation, 30 (1), 244-249. [张浩, 吕茂奎, 江军, 蒲晓婷, 王恩熙, 邱睵, 谢锦升 (2016). 侵蚀红壤区植被恢复对表层与深层土
壤有机碳矿化的影响. 水土保持学报, 30 (1), 244-249.]

Zhang L, Zhang DL, Mao ZJ (2017). Characteristic mineralization of soil organic carbon in different successional series of broadleaved Korean pine forests in the temperate zone in China, Acta Ecology Sinica, 37, 6370-6378. [张玲, 张 东来, 毛子军 (2017). 中国温带阔叶红松林不同演替系 列土壤有机碳矿化特征. 生态学报, 37, 6370-6378.]

Zhao M, Zhou J, Kalbitzb K (2008). Carbon mineralization and properties of water-extractable organic carbon in soils of the south Loess Plateau in China. European Journal of Soil Biology, 44, 158-165.

Zhou YY, Jia XH, Zhao X, Chen GX, Gao YH, Wu P (2011). Soil carbon mineralization potential under different configuration of vegetation. Chinese Journal of Ecology, 30, 2442-2448. [周玉燕, 贾晓红, 赵昕, 陈国雄, 高艳红, 吴攀 (2011). 不同植被配置下土壤碳矿化潜力. 生态学 杂志, 30, 2442-2448.]

Zhu RH, Zheng ZC, Li TX, Zhang XZ, He SQ, Wang YD, Liu T, Li W (2017). Dynamics of soil organic carbon mineralization in tea plantations converted from farmland at Western Sichuan, China. PLOS ONE, 12(9), e0185271. DOI: 10.1371/journal.pone.0185271.

特邀编委: 代力民 责任编辑: 李 敏 